\title{
Comparative Analysis of the Reliability and Validity Coefficients of WAEC, NECO and NABTEB Constructed Mathematics Examination
}

\author{
Prof. S. O. Bandele
}

Ekiti State University, Ado-Ekiti, Ekiti State, Nigeria.

\section{Dr. A. E. Adewale}

Ekiti State Board for

Technical \& Vocational Education, Ado-Ekiti, Ekiti State, Nigeria.

\section{Doi:10.5901/jesr.2013.v3n2p397}

\begin{abstract}
This study compared the reliability and validity co-efficient of mathematics examinations constructed by the West Africa Examination Council (WAEC), National Examinations Council (NECO), and National Business and Technical Examination Board (NABTEB), as a way to ascertain the extent in which these examination are comparable and met the required standard of a well standardized test in terms of reliability and validity. All the final year students of all Secondary School Students and Technical College Students in Nigeria constituted the population for the study. A total of 720 students were used as sample out of which 120 students were used for Test-retest method and the rest 600 students for other methods of estimating reliability and validity coefficients. The researcher adopted past WAEC, NECO and NABTEB mathematics questions as instruments for the study.Two hypotheses were raised, one on reliability and the other on validity and the two hypotheses were tested at 0.05 level of significance using Z-test, Fisher's Transformation and Hotelling Williams Test. The results of the findings showed that WAEC, NECO and NABTEB mathematics achievement Examinations are highly reliable and valid. It also showed that the Examination bodies are comparable and equivalent.
\end{abstract}

Keywords Comparative, WAEC, NECO, NABTEB. Mathematics Validity, Reliability, Examination

\section{Introduction}

The setting of public examination is highly skilled and professional. It involves not only the setting of questions and devising activities of testing the achievement of a comprehensive range of curriculum objectives, but also of ensuring that many different examiners and script markers work to the same standard. The standard of achievement has to be established not only for each subject of paper, but care has to be taken to ensure that the levels expected in one curriculum subject are comparable with those of all other subjects.

Hendrikz (1986), also emphasized further that public examinations can, by analyzing the spread of result, give information about the relative strengths and weakness of the teaching and learning of different subjects in different schools and by different groups of candidate.

In Nigeria, two examining bodies WAEC and NECO are responsible for the award of the Senior Secondary School Leaving Certificate (SSSC) while NABTEB is another examining body responsible for the award of National Technical Certificate, (NTC) and National Business Certificate (NBC) ordinary level. Despite the fact that the certificate being awarded by these three examining bodies are said to be equivalent, yet, stake holders in the education sector doubts the equivalence.

The researcher therefore intends to approach the issue of the equivalence of all ordinary level certificates being awarded by WAEC, NECO and NABTEB in terms of the reliability and validity of the examinations used for the award of the certificates. Test reliability and validity are two technical properties of a test that indicate the quality and usefulness of that test. Reliable assessment tools produce dependable, repeatable and consistent 
information about people. A well standardize examination should therefore be reasonably valid, reliable and usable.

Bandele (1989), pointed out that Assessment is an integral part of the educations system, which includes, internal (school) and external (public) examinations and continuous assessment. While Alonge (1999), pointed out that the use of assessment in Nigeria schools has been misleading, in the sense that children and parents had the impression that all that matters in school today is to obtain a certificate at all cost at the end of a course.

This issue of forcefully obtaining certificate at the detriment of acquisition of knowledge has caused a great havoc to the Education sector in Nigeria. Hence, making the standard of Education at the secondary level, be fluctuating in terms the reliability and validity. Some believed that the standard is increasing and high while many were saying that it is decreasing and low. Meanwhile, the examinations being conducted by these examination bodies were observed to have no longer been valid and reliable. Many believed that WAEC examinations are more reliable than NECO and NABTEB Examinations while some people believed that NECO Examinations are more standard than WAEC and NABTEB examinations.

Hence, there is need to investigate and re-determine the validity and reliability coefficients of WAEC, NECO and NABTEB constructed Examinations and make analytical comparation, so as to know which of these examination bodies is conducting more reliable and valid examinations.

\section{Purpose of the Study}

The purpose of this study was to investigate and determine the reliability and validity coefficients of WAEC, NECO and NABTEB constructed mathematics Examinations and compare same, so as to determine which of the three examination bodies are conducting more reliable and valid examinations.

\section{Statement of the Problem}

The followings are the problems enlisted for solution in this study:

1) Are the WAEC, NECO \& NABTEB constructed Mathematics Examinations reliable?

2) Are the WAEC, NECO \& NABTEB constructed Mathematics Examinations valid?

3) Are the WAEC, NECO \& NABTEB constructed Mathematics Examinations equivalently reliable?

4) Are the WAEC, NECO \& NABTEB constructed Mathematics Examinations equivalently valid?

\section{Research Hypotheses}

The following research hypotheses were raised and tested at 0.05 level of significant.

Ho1: There is no significant difference in the reliability coefficients of WAEC, NECO and NABTEB constructed mathematics Examinations

Ho2: There is no significant difference in the construct validity coefficients of WAEC, NECO and NABTEB constructed mathematics Examinations

\section{Research Design}

The researcher adopted survey research design for this study which also involved the use of correlation design.

Fig. 1 Correlational Design

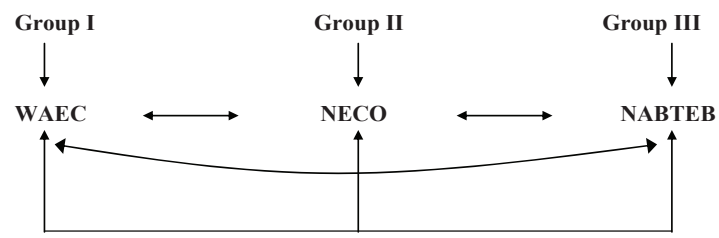


The sampled students were divided into three groups (I, II \& III). Group I was subjected to WAEC, group II to NECO and group III to NABTEB Mathematics Examinations as shown in fig I. The three groups possessed the same characteristics such as same syllabi, same period of learning and of the same educational level. Hence, they are considered to be homogeneous. A correlation analysis was carried out between WAEC and NABTEB, NABTEB and NECO and WAEC and NECO using appropriate statistical method.

\subsection{Population}

The population for this study consisted of all the final year students of both the Government and Public Secondary Schools in Nigeria and all the final year students of the Government Technical Colleges in Nigeria.

\subsection{Sample and Sampling Techniques}

A total of 720 final year students were selected to represent the entire population out of which 120 students were selected and used for the Test-retest method of estimating the reliability coefficients. And for the rest 600 students, 450 students were selected from the Government and Public Secondary Schools and the remaining 150 students selected from the Government Technical Colleges. The schools were selected from three states out of the six states of the South West Geo-Political Zone of Nigeria; for effective administration of the research instrument. The three states include: Ondo State, Osun State and Ekiti State. Moreover, a multi-stage sampling technique was used for the selections.

\subsection{Research Instruments}

Past WAEC, NECO and NABTEB Mathematics Examinations were randomly selected and adopted as instruments for this study. These are ready made standardized questions.

\subsection{Administration of the Instrument}

The selected students in each school were divided into three groups (I, II and III) and the groups were made to take WAEC, NECO and NABTEB mathematics Examinations respectively. The scores obtained were thereby used as data.

\subsection{Data Analysis}

All data obtained were analysed descriptively and inferentially using appropriate statistical method. Z-test, Hotelling Williams test and Fisher's Transformation test were used to test the two hypotheses.

\section{Results \& Discussion}

The results of the descriptive analysis of the data and that of the tests of the hypotheses are shown in the tables below.

Table I. Table of reliability coefficients of WAEC, NECO \& NABTEB Exams.

\begin{tabular}{|c|c|c|c|c|c|c|c|c|c|c|}
\hline \multirow[b]{3}{*}{ Exam Body } & \multicolumn{10}{|c|}{ METHODS } \\
\hline & \multicolumn{2}{|c|}{ Test-retest } & \multicolumn{2}{|c|}{ Split half } & \multicolumn{2}{|c|}{ rKR21 } & \multicolumn{2}{|c|}{ Modified Rkr21 } & \multicolumn{2}{|c|}{ Rkr20 } \\
\hline & $\mathrm{N}$ & $r$ & $\mathrm{~N}$ & $r$ & $\mathrm{~N}$ & $r$ & $\mathrm{~N}$ & $\mathrm{R}$ & $\mathrm{N}$ & $r$ \\
\hline WAEC & 40 & 0.795 & 200 & 0.815 & 40 & 0.78 & 40 & 0.711 & 40 & 0.80 \\
\hline NABTEB & 40 & 0.793 & 200 & 0.752 & 40 & 0.83 & 40 & 0.845 & 40 & 0.84 \\
\hline NECO & 40 & 0.904 & 200 & 0.512 & 40 & 0.87 & 40 & 0.905 & 40 & 0.92 \\
\hline
\end{tabular}


Table II. Z - Test summary table for reliability coefficients of WAEC, NECO \& NABTEB Mathematics Achievement Tests

\begin{tabular}{|l|l|l|l|l|l|l|}
\hline Exam Body & $\mathbf{N}_{\mathbf{1}}$ & $\mathbf{r}_{\mathbf{1}}$ & $\mathbf{N}_{\mathbf{2}}$ & $\mathbf{r}_{\mathbf{2}}$ & $\mathbf{Z}_{\text {cal }}$ & $\mathbf{Z}_{\text {tab }}$ \\
\hline WAEC & 40 & 0.795 & 200 & 0.815 & 0.32 & 1.96 \\
\hline NABTEB & 40 & 0.793 & 200 & 0.752 & 0.57 & 1.96 \\
\hline NECO & 40 & 0.904 & 200 & 0.52 & 5.18 & 1.96 \\
\hline
\end{tabular}

\section{$P \leq 0.05$}

Table III. Fisher Z transformation showing the confidence limit of the reliability coefficients

\begin{tabular}{|l|l|l|}
\hline Exam Bodies & Reliability Coefficient & Confidence Limit \\
\hline WAEC & 0.8 & $(0.65,0.89)$ \\
\hline NABTEB & 0.8 & $(0.65,0.89)$ \\
\hline NECO & 0.5 & $(0.36,0.77)$ \\
\hline
\end{tabular}

Table IV. Z - Test of significant different of validity coefficients using independent samples

\begin{tabular}{|l|l|l|l|l|l|l|}
\hline Exam Body & $\mathbf{N}_{\mathbf{1}}$ & $\mathbf{r}_{\mathbf{1}}$ & $\mathbf{N}_{\mathbf{2}}$ & $\mathbf{r}_{\mathbf{2}}$ & $\mathbf{Z}_{\text {cal }}$ & $\mathbf{Z}_{\text {tab }}$ \\
\hline WAEC & 40 & 0.11 & 200 & 0.28 & 0.99 & 1.96 \\
\hline NABTEB & 40 & 0.10 & 200 & 0.34 & 1.42 & 1.96 \\
\hline NECO & 40 & 0.01 & 200 & 0.19 & 1.01 & 1.96 \\
\hline
\end{tabular}

Table V. Hotelling Williams test of significance difference of validity coefficients using dependent samples

\begin{tabular}{|l|l|l|l|}
\hline Exam Body & $\mathbf{N}_{\mathbf{1}}$ & $\mathbf{Z}_{\text {cal }}$ & $\mathbf{Z}_{\text {tab }}$ \\
\hline WAEC & 40 & 1.56 & 1.96 \\
\hline NABTEB & 40 & 0.498 & 1.96 \\
\hline NECO & 40 & 1.49 & 1.96 \\
\hline
\end{tabular}

\section{$P \leq 0.05$}

For hypothesis one, two independent samples of 40 students and 200 students were used for each of WAEC, NECO and NABTEB Mathematics Achievement Tests respectively and the result was shown in table II. The result showed that the Z-calculated values are less than the Z-Critical values for WAEC and NABTEB while Z-calculated for NECO was greater than the Z-table of 1.96 at 0.05 level of significance. Hence, there was no significant difference in the reliability coefficient of WAEC and NABTEB examinations while that of NECO was significantly different.

The significance difference therefore led to the use of Fisher $Z$ transformation to establish the confidence limit (interval) of the reliability coefficients and the result was as shown in table III which put the maximum limit of the reliability coefficients of WAEC, NABTEB and NECO at 0.89, 0.89 and 0.77 respectively. Hence, there was no significance different in the reliability coefficient of WAEC, NABTEB and NECO mathematics Examinations.

Hypothesis two states that there is no significant difference between the construct validity coefficients of WAEC, NECO and NABTEB Mathematics Achievement Examinations. Z-test of significance difference between correlation coefficients of independent samples and Hotelling Williams test of significance difference between correlation coefficients of dependent samples are used to test this hypothesis and the result was shown in table IV,$N_{1}$ and $N_{2}$ are independent samples with their corresponding validity coefficients $r_{1}$ and $r_{2}$. Z-values were calculated for each sample as $Z_{1}$ and $Z_{2}$ with corresponding $r_{1}$ and $r_{2}$ because of the independent variables and $Z$-test was used to obtain $Z$ calculated value as shown in the table. The result therefore showed that all $Z$ calculated values are less than the $Z$ critical value of 1.96 at $P \leq 0.05$. The hypothesis was therefore accepted that is, there was no significance difference between the construct validity coefficients of WAEC, NECO and NABTEB mathematics achievements, using independent samples. Hotelling Williams's test of significance difference using dependent sample, was also used to test for the difference between two correlation coefficients $r_{x y}$ and $r_{x z}$. The 
excess of this is to show whether variable $X$ has the same correlation with the two other variables $Y$ and $Z$ where $X, Y$ and $Z$ are WAEC, NECO and NABTEB respectively.

The result as shown in table $V$ showed that all Z-calculated values are less than the Z-critical value of 1.96 and the hypothesis was therefore accepted. Hence, there was no significant different between the construct validity coefficients of WAEC, NECO and NABTEB mathematics examinations.

\section{Discussion}

Different statistical methods like Test-retest, Split half, Kuder-Richardson 20 and 21 and Modified KuderRichardson 21 were used to determine the reliability coefficient as shown in table I and the results clearly showed that WAEC and NABTEB results are equivalent and highly reliable. Though NECO recorded a reliability coefficient of 0.512 when split half method was used, yet the use of Fisher $Z$ transformation showed the confidence limits to be between 0.7 and 0.9 for WAEC, 0.7 and 0.9 for NABTEB, and 0.4 and 0.8 for NECO.

Therefore, the upper limit point for WAEC, NECO and NABTEB stood at 0.9, 0.8 and 0.9 respectively and this clearly contradicted the finding of Adeniran (2000) that showed that NECO is inferior to WAEC in all standards.

If WAEC and NECO are equivalent by the use of measure of prior outcomes, measure of concurrent outcomes, measure of subsequent outcomes and the use of expert judgement as reported by Newton (1997), Bell (2000) and Wuiot (2001) WAEC, NECO and NABTEB results are also equivalent by the use of comparability of their reliability and validity coefficients.

The use of construct validity in determining the validity coefficients was to measure the extent of achievement of the learning instructions which was displayed in the result of the findings. This is in support of Leovnger (1957) who believed that construct validity is the essence of validity and that all other types of validity are subsumed under it.

\section{Conclusion}

The findings therefore revealed that the three Examination bodies WAEC, NECO and NABTEB which are responsible for the final assessment and Evaluation of the Senior Secondary School Students and Technical School Students are still constructing standardized achievement tests. A critical analysis of the findings also showed that WAEC, NECO and NABTEB Examinations are highly valid and reliable and none can be said to be inferior or superior to the other in terms of reliability and validity.

\section{Recommendations}

The following recommendations were therefore made based on the result of the findings:

$>$ WAEC, NECO and NABTEB Examinations and Certificates should be given equal recognitions for certification and admission purposes.

$>\quad$ There should be a Joint Evaluation Committee that will comprise representatives of WAEC, NECO and NABTEB and other stake holders that will serve as monitoring team for the constructions of examination items, conduct of examinations and certifications.

\section{References}

Adeniran, .T. (2000): NECO certificate valid for varsity admission. An Article Published in the Punch Newspaper of Tuesday, 29th February, 2000. Pg 29.

Adewale, A.E. (2008): Comparative analysis of the psychometric properties of WAEC, NECO and NABTEB Mathematics Achievement Tests. Ph.D Thesis (EKSU) Ado Ekiti, Nigeria.

Alonge, M.F. (1989): Psychometric effects of two probability models. Ado-Ekiti, Adebayo Press Nigeria Ltd.

Bandele, S.O. (2004): Educational research in perspective. Ibadan; Niyi Commercial and Printing Ventures.

Hendrikz, .T. (1986): Introduction to educational psychology. London Macmillan Publishers Ltd. 
Kathryn E. Hill, G.M.C.H., \& GINDIRI (1999): Problems encountered by visually handicapped Nigerian candidates in school and public examinations and some strategies to overcome them. A Document by the U.S. Department of Labour, Employment and Training Administration. 